\title{
EXPERIÊNCIAS BRINCANTES DE CRIANÇAS NO ESPAÇO ESCOLAR
}

\author{
PLAYING EXPERIENCES OF CHILDREN IN SCHOOL SPACE
}

EXPERIENCIAS BRINCANTES DE NIÑOS EN EL ESPACIO ESCOLAR

Cleomar Ferreira Gomes ${ }^{1}$

\begin{abstract}
Resumo
O presente texto traz como investigação, na cultura do brinquedo e da brincadeira, as alegorias brincantes narradas por professoras na/da Educação Infantil. Serviu de instrumento para a coleta dos dados, um questionário semiestruturado, aplicado às participantes, com dados coletados numa visita aos seus loci de trabalho, com o qual identificamos a noção que as professoras têm de brincadeira, o método que utilizam para desenvolver atividades lúdicas no ambiente escolar, e suas narrativas que alegorizam tais atividades, na esperança didática de obter algum resultado positivo na educação de crianças pequenas com o uso de brinquedos e brincadeiras. Antes de lidar com essas informações, supomos apropriado considerar aquilo que alguns teóricos dos termos - brinquedos e brincadeiras - relevam como válidos pela pena da ciência. Foi muito rico para pesquisadores e professoras saber como elas lidam com esses conceitos no campo de trabalho e como aproveitam esses conhecimentos adquiridos nos cursos e estudos para, na intervenção, requerer algum resultado prático. Para a tarefa formulamos algumas questões que pudessem pinçar esses conhecimentos no modus operandi de cada uma dessas professoras. As respostas revelam que os discursos são favoráveis à entrada de brinquedos, jogos e brincadeiras no espaço escolar porque são importantes para o curso natural do desenvolvimento das crianças. De modo mais estrito foi possível analisar as formas de envolvimento destas professoras, e aquilo que narram como percepções, noções e mesmo intervenções pedagógicas, quando alegorizam ou melhor representam as funções estéticas e pedagógicas que as brincadeiras e os brinquedos se submetem ao entrar nos espaços de escolarização.
\end{abstract}

Palavras-chave: Educação Infantil. Alegorias Brincantes. Intervenção pedagógica.

\begin{abstract}
The present text brings as investigation, in the culture of the toy and of the joke, the playing allegories narrated by teachers in the/of Infantile Education. It was used as a data collection instrument, a semi-structured questionnaire, applied to the participants, with data collected during a visit to their work loci, with which we identify the notion that the teachers have as a game, the method they use to develop play activities in the and their narratives that allegorize such activities, in the didactic hope of obtaining some positive result in the education of young children with the use of toys and games. Before dealing with this information, we suppose it appropriate to consider what some theorists of the terms - toys and games - stand for validity by the pen of science. It was very rich for researchers to know how they deal with these concepts

\footnotetext{
${ }^{1}$ Doutor em Educação pela USP. Professor Titular da Universidade Federal de Mato Grosso (UFMT). Líder do Grupo de Estudos e Pesquisas sobre a Corporeidade e Ludicidade (GEPCOL). E-mail: gomescleo.cg@ gmail.com
} 
in the field of work and how they take advantage of the knowledge acquired in the courses and studies to require some practical result in the intervention. For the task we formulated some questions that could squeeze this knowledge in the modus operandi of each one of these teachers. The answers reveal that the discourses are favorable to the entrance of toys, games and games in the school space because they are important for the natural course of children's development. More strictly, it was possible to analyze the forms of involvement of these teachers, and what they narrate as perceptions, notions and even pedagogical interventions, when they allegorize or better represent the aesthetic and pedagogical functions that play and toys undergo when entering the spaces of schooling.

Keywords: Early Childhood Education. Playing allegories. Pedagogical intervention.

\section{Resumen}

El presente texto trae como investigación, en la cultura del juguete y de la broma, las alegorías brincantes narradas por profesoras en la Educación Infantil. Se utilizó un instrumento para la recolección de datos, un cuestionario semiestructurado, aplicado a las participantes, con datos recogidos en una visita a sus loci de trabajo, con el cual identificamos la noción que las profesoras tienen de broma, el método que utilizan para desarrollar actividades lúdicas en el trabajo el ambiente escolar, y sus narrativas que alegorizan tales actividades, en la esperanza didáctica de obtener algún resultado positivo en la educación de niños pequeños con el uso de juguetes y juegos. Antes de hacer frente a esa información, suponemos apropiado considerar lo que algunos teóricos de los términos - juguetes y juegos - relevan como válidos por la pena de la ciencia. Fue muy rico para investigadores y profesoras saber cómo ellas lidian con esos conceptos en el campo de trabajo y cómo aprovechan esos conocimientos adquiridos en los cursos y estudios para, en la intervención, requerir algún resultado práctico. Para la tarea formulamos algunas cuestiones que pudieran pinzar esos conocimientos en el modus operandi de cada una de esas profesoras. Las respuestas revelan que los discursos son favorables a la entrada de juguetes, juegos y juegos en el espacio escolar porque son importantes para el curso natural del desarrollo de los niños. De modo más estricto fue posible analizar las formas de implicación de estas profesoras, y aquello que narran como percepciones, nociones e incluso intervenciones pedagógicas, cuando alegorizan o mejor representan las funciones estéticas y pedagógicas que los juegos y los juguetes se someten al entrar en los espacios de escolarización.

Palabras clave: Educación infantil. Alegorías Brincantes. Intervención pedagógica.

\section{INTRODUÇÃO}

O brincar infantil vem sendo explorado e explicado por diferentes áreas de conhecimento, dentre elas, a psicologia, a antropologia, a sociologia, a filosofia, que há muito têm demonstrado uma importância ao assunto, quando se refere à educação dos pequenos. O destaque fica para a pedagogia, que se utiliza do "brincar infantil" em seus contextos educacionais, em suas organizações curriculares, em seus cursos de formação, quando vê na Educação Infantil, uma possibilidade de se pensar a realidade escolar que não prescinda ao jogo, o brinquedo e a brincadeira em suas propostas de trabalho. Há sempre uma indicação para 
se pensar o brincar enquanto a necessidade basilar, assim como a nutrição, a higiene, a habitação, a educação. Brincar pode apoiar a criança nos seus rituais de desenvolvimento físico, afetivo, intelectual, social e moral, pois, através das atividades lúdicas, ela pode vir a formar/entender conceitos, relacionar ideias, estabelecer relações de lógica, desenvolver a expressão oral e corporal, reforçar habilidades sociais, reduzir a agressividade e integrar-se na sociedade, além de construir seu próprio conhecimento.

A relação entre a hospitalidade e o brincar fica clara naquilo que Camargo (2015) chama de tempos e espaços da hospitalidade: a escola é um espaço e o brincar é um tempo da hospitalidade.

\section{Material e Métodos}

Esta pesquisa utilizou como instrumento para a coleta dos dados um questionário semiestruturado aplicado às participantes, com dados coletados numa visita aos seus loci de trabalho, com o qual identificamos a noção que as professoras têm de brincadeira, o método que utilizam para desenvolver atividades lúdicas no ambiente escolar, e suas narrativas que alegorizam tais atividades, na esperança didática de obter algum resultado positivo na educação de crianças pequenas com o uso de brinquedos e brincadeiras.

\section{Brinquedo e Brincadeira: Da importância das noções}

Esses vocábulos, no terreno da escola de crianças pequenas se traduzem como atividades que se situam, preferencialmente, no campo simbólico, como diz Château (1987): no solo paradigmático dos jogos de faz de conta. Eles nascem de uma força criativa que tem o ser humano, as crianças por excelência, de exercer a sua rubrica lúdica, isto é, uma capacidade natural de fazer coisas, manipular objetos, produzir fatos e de inventar histórias que põem em ação um preenchimento do tempo de sua existência subjetiva e social.

Essas atividades devem ter a preocupação primordial de ajudar as crianças a estimularem-se para sua criatividade, à aprendizagem das regras sociais, e a se libertarem dos "horrores do mundo de gigantes" como prefere Benjamin (1984, p. 64), porque esse mundo é feito de obrigações pesadas demais para a cultura infantil que tem outra realidade para dar conta. É bom lembrar que essa criança a que se refere esse autor se materializaria numa "criança ideal" e não nas "crianças reais" que conhecemos, sobremaneira aquelas dos países 
mais empobrecidos, onde têm, desde cedo, a sua infância lúdica esboroada pelas dificuldades existenciais (fome, escolarização precária, insalubridade, riscos sociais, maus tratos) e que doravante serão impelidas aos apelos do mundo do trabalho precoce.

\section{As brincadeiras}

É bom repetir que o termo brincadeira não existe noutra cultura linguística como nós o utilizamos por aqui. Muitas vezes se confunde com atividade lúdica, que não consegue separar aquilo que dissimula, que simboliza e que dá prazer. A qualidade que tem um objeto (brinquedo) ou uma atividade (brincadeira) é que faz despertar um estado lúdico, a espontaneidade, o senso de humor e a alegria. É uma atividade livre, instável, voluntária e não sujeita a ordens externas ao seio da própria brincadeira. $\mathrm{O}$ professor de crianças pequenas deve saber que é precisamente em tal fato que reside sua espontaneidade ou aquilo que Huizinga (1990), considerou como sendo a sua primeira característica.

Desse modo poderíamos acentuar que a brincadeira é a ação de brincar, uma atividade autotélica, composta de regras flexíveis, que carrega a função precípua de entreter e que escorre em tempos e espaços à escolha do brincador, de caráter atemporal, sendo mais exclusiva da Cultura Infantil.

\section{Dos brinquedos e de crianças}

Há, segundo o filólogo Houaiss (2007, p. 514), cinco possibilidades para definir brinquedo: 1) objeto com que as crianças brincam; 2) brincadeira ou jogo; passatempo, distração; 3) pessoa com quem se faz o que se quer; joguete; 4) coisa que não é séria; brincadeira; 5) coisa fácil de fazer ou de pouca monta.

$\mathrm{Na}$ maioria dos autores, quando se lê as palavras brinquedo e brincadeira, é fácil perceber um traço semântico em que se cruzam o verbo brincar. No seu "Educação Lúdica", Almeida (1990) afirma que o brinquedo faz parte da vida da criança: simboliza a relação pensamento-ação e, portanto, a matriz de toda a atividade linguística, ao tornar possível o uso da fala, do pensamento e da imaginação.

Se o primeiro brinquedo da criança é o próprio corpo, que com ele começa a explorar, já nos primeiros meses de vida, a chegada dos objetos, logo depois continuam a produzir 
estimulações visuais, auditivas e cenestésicas, quando este seu brincador passa a ser o protagonista de sua própria ação. A partir de então o brinquedo, pela função, imagem e representação dos objetos, instala sua presença na vida da criança, do adolescente e até mesmo do adulto.

Para Almeida (1990, p. 26), o mundo do brinquedo é um mundo composto de imaginação, imitação e representação, fazendo parte de uma vontade de crescer e de se desenvolver. Quando brinca com uma boneca ou um utensílio doméstico em miniatura, a criança exercita a manipulação dos objetos, compondo-os, designando-lhes um espaço e uma função, dramatizando suas próprias relações com aquilo que esses objetos representam e eventualmente seus conflitos.

Para Benjamin (1984) o conteúdo de um brinquedo não determina a brincadeira da criança. Ao contrário, o ato de brincar é que revela o conteúdo do brinquedo. A criança, diz Benjamin, "ao puxar alguma coisa, torna-se cavalo; ao brincar com areia, torna-se padeiro; ao esconder-se, torna-se ladrão ou guarda" (Idem, p. 69-70). Para uma criança, quanto mais atraente ou sofisticado for o brinquedo, mais distante estará de um valor como instrumento de brincar. Quanto mais aperfeiçoado à semelhança do real, tanto mais se desvia da brincadeira livre e viva. Segundo o autor, nada é mais adequado à criança do que associar em suas construções os materiais mais heterogêneos como pedras, bolinhas, papéis, madeira. Um simples pedaço de madeira, uma figurinha ou uma simples pedrinha reúne em sua solidez, na unidade de sua matéria, uma exuberância das mais variadas figuras: ninguém é mais sábio em relação aos materiais e ao que faz com eles do que a criança.

A fabricação de brinquedos é sempre condicionada ao ponto de vista do adulto e das coletividades. Os brinquedos aí produzidos demonstram como o adulto se coloca com relação às crianças e ao mundo delas. O brinquedo, pela pena "romântica" de Benjamin (p. 74), "é uma criação para a criança, quando ao contrário, deveria ser uma criação da criança”. Jamais são os adultos os que executam a correção mais eficaz dos brinquedos. Mesmo que essa correção seja feita por pedagogos ou "entendidos" fabricantes, não é nunca melhor do que a que fazem as próprias crianças, durante as brincadeiras. Uma boneca "principesca" que se quebrou, no reparo feito pela criança pode transformar-se numa eficiente companheira ou, nos termos do próprio Benjamin (p. 65), numa “camarada proletária na comuna lúdica das crianças”. 
Ainda pela leitura de Benjamin, o brincar significa um libertar-se dos horrores do mundo através da reprodução miniaturizada: as crianças, rodeadas por um mundo de gigantes, criam para si, enquanto brincam um pequeno mundo próprio. Noutras palavras, ou reinterpretando este autor, a criança se protege no mundo que compõe, onde as leis são feitas pela própria cultura - a cultura infantil. Nesta, a lei maior é a brincadeira, o brincar movido pela aventura e pela alegria.

Cascudo (1988, p. 146), com seu dicionário do folclore brasileiro, apresenta dois diferentes sentidos para brinquedo. Num primeiro, tanto brinquedo como brincadeira são sinônimos de jogos, rondas, divertimentos tradicionais infantis, cantados, declamados, ritmados ou não, de movimento. Num segundo, o brinquedo é um objeto material para brincar - carro, arco, boneca, soldados, papagaio, figuras - assim como a própria ação de brincar brinquedo de dona-de-casa, de cabra-cega, de galinha-gorda, de chicote queimado. Como se vê nessas duas acepções há por um lado o dinamismo de uma atividade e doutra parte o leiaute de um objeto em que vigoram a experiência lúdica.

Algumas informações de Cascudo nos pareceram servir em especial para o assunto do presente ensaio. A primeira diz respeito às brincadeiras infantis mais preferidas. No dizer do autor, essas brincadeiras mais populares (idem, p. 146) são as mais universais e de livre movimentação individual. Essas brincadeiras dificilmente desaparecem: são das mais admiráveis constantes sociais, transmitidas por via oral, abandonadas numa geração e reerguida na outra, numa sucessão ininterrupta de movimento e de canto. A segunda diz respeito às menos preferidas das crianças. "São as que restringem o direito de alguma improvisação no gesto e na carreira. Esgotam rapidamente o desejo de brincar e monotonizam o grupo". (Idem, ibidem loc. cit.). São brincadeiras que não promovem a excitação, não têm uma força ou vivacidade tal que possam absorver por completo o brincador. Seriam, numa linguagem própria de criança, aquelas brincadeiras sem graça, xoxas ou "chatas".

Para autores da língua francesa como Brougère (1995) e Manson (2002), por exemplo, a noção de brincadeira — de "jogo" - precisa ser relativizada quando se pretende pesquisar sobre o assunto. Brougère recomenda partir do princípio de que jogo - a brincadeira — "é uma palavra complexa e que é preciso às vezes, um consenso no que é”, pelo seu caráter polimorfo. Há pesquisadores que se interessam pela utilização da palavra jogo, "pelo discurso sobre o jogo", por uma reflexão sobre a palavra jogo, seu campo semântico, apesar e além de 
sua função educativa e, portanto, o "centro do trabalho" é a significação mais do que o jogo em si. O autor inclui-se entre aqueles que não se interessam pelo que ele denomina como "retórica" sobre o jogo, à guisa do que faz Sutton-Smith (1997) em sua obra "The ambiguity of play". Para Brougère essa reflexão é secundária, quando nos dirigimos às atividades endereçadas às crianças. Mas podemos nos interessar pelo uso da palavra, mostrando "o que as pessoas chamam de jogo, o que os mais velhos e as crianças chamam de jogo", isto é, pensar a questão da palavra jogo, "mas em relação ao que consideram aqueles que brincam e aqueles que não brincam. São elas que podem dominar a resposta, não o pesquisador". Pode ser, explica Brougère, que venhamos a descobrir que é importante o que é chamado de jogo (brincadeira), mas isso se descobrirá no campo, nas observações, na conversação. Num primeiro tempo, o que interessa é ver o que as crianças fazem.

No dizer de Manson, (2001) é preciso desconfiar dos conceitos que, “forjados nos anos 20 ou nos anos 80, foram talvez muito úteis naqueles momentos, mas podem hoje vir a bloquear uma pesquisa. É preciso que o pesquisador - no caso o que investiga sobre brinquedo/brincadeira - retome todos esses conceitos, vocabulário técnico ou especializado da questão e reponha a questão como fazem os filósofos: Será que ainda hoje posso usar esse mesmo conceito? Será que essa ideia não está caduca para meu tempo?” É uma certa dúvida cartesiana quanto ao conhecimento que não se pode ter sobre uma questão. Se a gente começa com uma certeza, a gente chega com a mesma certeza... Segundo Manson, qualquer categorização inicial é monolítica, enquanto a vida real, muito frequentemente, surge nuançada. Por fim, à semelhança de Brougère, Manson sugere que um tratamento dos dados obtidos numa coleta que atente para a "delicadeza do vivido" - é que permitirá saber a que tipo de conceito a gente chega e não forçosamente àquele que a gente tinha em mente, no começo da pesquisa.

Outro autor que alerta o pesquisador sobre as armadilhas das categorizações ou conceitos iniciais "muito fixos" — os pré-conceitos — e da importância da experiência que é preciso dar ao que os sujeitos denominam jogo é o americano Tobin (1997). Mais importante que o nome conferido ao jogo - brincadeira - e do que as categorizações dos brinquedos é saber o que as crianças estão pensando enquanto estão brincando ou jogando. "Na pesquisa, diz esse autor, nós necessitamos de entrevistas, de técnicas, de métodos que possam compreender os espíritos que estão jogando... O que podemos fazer? Observar... Precisamos conversar com 
as crianças. Elas têm muito a nos ensinar, a ver coisas importantes que nos façam penetrar no mundo da ciência."

No intuito de nos aproximar do que realmente é o brinquedo e a brincadeira e as prováveis diferenças entre os dois termos, depois de ter lido gente autorizada a respeito do assunto, buscamos das próprias crianças aquilo que observamos e ouvi das professoras de crianças pequenas, numa contribuição, aqui posta, como um reforço teórico a partir do empírico.

\section{Da pesquisa feita - o método}

O método, segundo Lakatos e Marconi (2010, p. 65) "é um conjunto das atividades sistemáticas e racionais que, com maior segurança e economia, permite alcançar o objetivo conhecimentos válidos e verdadeiros - traçando o caminho a ser seguido, detectando erros e auxiliando as decisões do cientista"; e se para Cervo e Bervian (2002, p. 23-25), não criamos um método, porque ele está intrinsecamente ligado ao assunto da pesquisa, considerando que a investigação brota do problema de eleição, por isso o uso desse conjunto de etapas de que se serve o método científico, para fornecer subsídios necessários na busca de um resultado para as questões norteadoras da pesquisa irá estimular o nascimento desse caminho que ajudará o pesquisador a realizar tal investigação, a desvelar seus mistérios e a produzir suas constatações, inspiradas pelas hipóteses de trabalho.

Foi se pautando por estas assertivas que entramos em campo, com - um método - ou critérios para a busca da explicação das questões ou dos problemas específicos, descritos no que seriam as brincadeiras vistas e feitas pelas professoras de crianças miúdas — da educação infantil.

Supondo que o brincar é o ato de manifestação da ludicidade, exercida por homens e animais filhotes, que envolve o ser brincante, que o brinquedo seria todo o material ou as "coisas" que se utilizam como objeto para brincar e que a brincadeira seria essa atividades simulada por nossa imaginação, "entramos em campo" com o objetivo cardeal de investigar a cultura do brinquedo e da brincadeira pela percepção das professoras da rede municipal da baixada cuiabana, enquanto professoras da primeira etapa, Educação Infantil, do Ensino Básico, e enquanto alunas da disciplina "Brinquedos e Brincadeiras no cotidiano da Educação Infantil", sob a nossa batuta. 
Em sua ementa essa disciplina reza pelas seguintes temáticas: $\mathrm{O}$ brincar como eixo curricular e sua prática no cotidiano da educação infantil. O brincar e suas teorias. A brincadeira na infância em diferentes abordagens: filosofia, antropologia, psicologia e sociologia da infância. O brincar como forma própria de a criança significar e apreender o mundo. Brincadeira e construção de conhecimento. Brincadeira como experiência de cultura. Brincadeira e culturas infantis. Jogo, brinquedo e brincadeira: definições e questões. A ludicidade como mediadora da ação da criança. As culturas infantis na contemporaneidade e o repertório de brinquedos, brincadeiras e práticas lúdicas ao longo da história. Os espaços e tempos do brincar em creches e pré-escolas.

Para tanto, aplicamos um questionário semiestruturado (questões em anexo) com as participantes da disciplina e com os dados coletados identificamos a noção que as professoras têm de brincadeira e o modo como desenvolvem esta atividade no ambiente escolar. De modo particular foi possível analisar as formas de envolvimento e intervenções destas profissionais no momento da brincadeira das crianças. Atividades práticas nas aulas da disciplina. Como atividades práticas propusemos e realizamos as seguintes brincadeiras: construção de Brinquedos cantados; Brincadeiras de roda, brincadeiras com o uso do corpo sem materiais e algumas intelectivas como "Jan-Ken-Pô"2 e o "Resta Um".

Como havíamos trabalhado as rubricas do jogo e da brincadeira segundo a obra "os jogos e os homens - a máscara e a vertigem" de Caillois (1990), todas as atividades que aplicamos em sala, sugerimos que fossem "banhadas" ou "molhadas", de molho com a essa teoria para que elas percebessem a serventia daquilo que chamamos de pressupostos teóricos, num exercício acadêmico de enxergar a teoria na prática e prática com a teoria, e que tentassem, numa alegoria, tentar irrigar a prática de cada uma.

\section{Significações e interações das professoras com as brincadeiras infantis}

Passamos, nesta seção, a mostrar aquilo pode caracterizar-se como o trato cotidiano dessas professoras e suas relações com as crianças da pré-escola ou creche, enquanto tais, no

\footnotetext{
${ }^{2}$ JAN-KEN-PÔ - Para saber mais sobre este jogo infantil - funcionamento, história e curiosidades.

${ }^{3}$ RESTA UM é um quebra-cabeça no qual o objetivo é, por meio de movimentos válidos, deixar apenas uma peça no tabuleiro. No início do jogo, há 21 peças no tabuleiro, dispostas com (seis, cinco, quatro, três, dois e uma peças) a formar um triângulo retângulo ou escaleno. Um movimento consiste em pegar uma peça e fazê-la "saltar" do tabuleiro, mexendo-se na horizontal (quantas peças quiser ou na vertical, apenas uma por vez), deixando os espaços em vazio. A peça que foi "saltada" é retirada do tabuleiro. O jogo termina quando restar apenas uma peça. O jogador vencedor será aquele deixar ao tabuleiro a última peça ao seu oponente.
} 
uso de brinquedos, brincadeiras e jogos. Este primeiro momento de descrição resulta da escuta de 30 dos 60 professores em exercício nessas unidade escolares, o que quer dizer as vozes da metade de todas as que se encontram "regendo classes" - que aqui chamaremos de "alunasprofessoras" - todas responsáveis pelas aulas de Educação Infantil - que chamaremos "professores de pré-escola", e que terão a sua identificação com um nome fictício, num acordo com todos eles que colaboraram com a investigação e que bem podem representar todas as professoras e os professores das unidades de pré-escolas da rede cuiabana de ensino da Educação Infantil.

Mostramos essas vozes na forma de seus fragmentos mais reveladores e materializados no papel a modo de serem enxergados e juntados aos comentários tirados da observação assistemática do grupo em sala de aula do curso, sejam na hora das brincadeiras e da construção dos brinquedos. Com base no que vimos mostrar, supomos ser possível caracterizar o cotidiano das professoras dessa "fatia" escolar, caracterizando, ao mesmo tempo, do ponto de vista das participantes, os brinquedos e as brincadeiras de sala e os de curso, assim como as relações existentes entre um brincar da escola para ensinar e um brincar do curso para aprender.

\section{O que alegorizam suas narrativas nos discursos e nas práticas}

Ficamos à vontade com a acepção da palavra alegoria ${ }^{4}$, naquilo que ela representa na sua função estética, muito mais que uma interpretação exegética, como fazem os textos sagrados. São sagrados para nós as falas, as percepções, as noções e o trabalho das professoras quando envolvem a aquisição de brinquedos e brincadeiras, que sob, apesar e além do sentido literal, pode representar outra coisa no sentido metafórico, assim como fazem as crianças quando se travestem de lobos, monstros, ogros e fadas. Desse modo particular, as brincadeiras feitas máscaras podem pôr em cena o nosso lado mais burlesco, caricato, mas também mais generoso. É com essa ambiguidade que as professoras encarram com seu trabalho, aquilo que os jogos, os brinquedos e as brincadeiras podem oferecer.

É muito comum quando professores de pré-escola, dizem sobre a usança de jogos, brinquedos e brincadeiras de crianças, em seu métier, o destaque à palavra importância, quase

\footnotetext{
${ }^{4}$ Vamos assumir com a etimologia do termo aquilo que o dicionarista Houaiss (2007, p. 146) trata como o modo de expressão representar pensamentos, ideias sob a forma figurada; acentua também como derivado do grego allégoría, que é formado de állos "outro" + agoreúó: "falar numa assembleia, falar em público, discorrer oralmente em público". Alegoria, também como dizer outra coisa além do sentido literal das palavras ou "significação encoberta".
} 
sempre acompanhada de uma utilidade na presença desses pré-textos enquanto estratégias, ou como o Método. Não é incomum também anexarem à palavra importância uma outra tão surrada quanto esta: o desenvolvimento. Desse modo, com a hibridação desses dois vocábulos chegamos à locução obsessiva na cultura escolar quando esta se dirige à função de ser importante porque ajuda no desenvolvimento de seus alunos. Embora essas mesmas professoras, às vezes se esquecerem que a palavra e a função carregam uma complexidade porque não é tão fácil nem de se perceber e muito menos de explicar como isso pode ocorrer no curso do crescimento de um indivíduo: o brincar pode ser mais que importante; pode requerer mais que manipular brinquedos; pode ir além do desenvolvimento, pode esconder ou mascarar, com a licença de cada alegoria algo que esteja subterrâneo. Não é incomum, os alunos, muitas vezes, simularem prestar atenção às aulas, quando seu corpo já está catapultado no recreio ou nas aulas lá da quadra.

Há teoristas que, quando tratam da função dos jogos, elegem uma matriz psicogenética, porque supõe que os nossos genes são capazes de carregar informações seletivas e de endereçar a outras gerações de modo natural. Um exemplo clássico seria quando uma criança aprende a jogar algum jogo sem nunca ter jogado. As informações atávicas auxiliam na aquisição dessa aprendizagem. Outros assumem que isso só é possível, no curso das interações que os indivíduos estabelecem com o meio ambiente e com as pessoas e objetos de seu entorno, sejam de modo objetivado - no caso da escola — ou de modo aleatório - na vida cotidiana.

Não importa, basta que exista uma escola e lá estarão os jogos, os brinquedos e as brincadeiras, que se resumirão em atividades lúdicas, porque a criança, dizendo de um jeito simples, precisa, merece e tem o direito de brincar. Mas nunca se fala de privilégios porque são "filhotes", assim como qualquer mamífero que têm muita energia para gastar.

Do questionário ${ }^{5}$ que aplicamos a essas professoras foi possível extrair algumas respostas que nos serviram de categorias de análise. Vamos, por eleição, nos concentrar nas narrativas que se remetem ao discurso de ser importante e das práticas de intervenções que ajudam no desenvolvimento das crianças.

\footnotetext{
${ }^{5}$ Para o questionário utilizado, foram formuladas essas questões, mas para este texto utilizaremos apenas aquelas que respondem aos discursos e práticas de intervenções: O que significa brincar para você? O que representa o brincar para a criança? Você faz intervenções quando as crianças estão brincando? Quando você era criança, costumava brincar de quê? Você costuma brincar com seus alunos? De quê? Qual é a brincadeira que você percebe que as crianças mais gostam de brincar com você? Você utiliza brinquedos no ambiente escolar com as crianças? Quais? Descreva a importância do brinquedo no ambiente escolar. Na sua percepção, o que acontece de bom quando as crianças brincam? De que forma o brincar reflete no futuro da criança?
} 


\section{Discurso sobre a importância}

O brinquedo, segundo essas professoras, carrega o potencial de enriquecer o mundo infantil, de desenvolver suas habilidades, criatividade e sua autonomia. Serve também como fuga das atividades em que as crianças devam fazer sentadas, o que facilita na manutenção do controle. Transforma o ambiente, transportando as crianças para a "terra" do faz de contas, para um ambiente de "magia" propício à aprendizagem. O ambiente se torna mais agradável, divertido e alegre. Contribui para um bom relacionamento entre professor e aluno nas relações interpessoais e é excelente forma de imprimir na criança o respeito às regras, necessário para a brincadeira e para a vida. Não se esquecendo de sempre de adotar o brinquedo mais adequado para cada faixa etária e incentivar as crianças ao cuidado com o brinquedo.

Essas falas abaixo podem melhor dizer o que a análise suscita:

É muito importante porque respeita a criança pelo simples fato de ser criança, deixando assim um ambiente menos formal e mais acolhedor. (Profa. Carmem - 25 anos).

O brinquedo é algo que as crianças gostam... aprendem como dividir, ter cuidado e sabem como usar no momento certo... É uma ferramenta que pode ser usada como um recurso na Educação Infantil. (Profa. Vera - 35 anos).

O brinquedo no ambiente escolar [...] lhes dá a liberdade de viajar na imaginação. (Profa. Helena - 27 anos).

... sua imaginação trabalha o seu raciocínio lógico e o seu intelecto. Onde a criança é livre para criar e recriar. (Profa. Denise - 30 anos).

... é através dele que a criança apreende e aprende sobre o mundo em que vive. (Profa. Marcela - 33 anos).

[...] o brinquedo dá vida ao ambiente escolar e estimula a imaginação das crianças. (Profa. Jaciara - 30 anos).

Uma outra categoria nos foi necessária para registrar o que elas, as professoras consideram como intervenção, que nós, por opção preferimos nominar de suas práticas. Ao serem perguntados se fazem intervenções quando as crianças estão brincando, as professoras responderam, na maioria que fazem; às vezes; raramente; sempre e há aqueles que preferem não fazer intervenção alguma.

Quanto ao tipo de intervenções, foram citadas algumas formas de explorar situações para estimular o desenvolvimento dos alunos, incentivar e encorajá-los a ter atitudes e inciativas de como potencializar a afetividade. Uma grande parte dos professores se posiciona sobre a necessidade de resolver conflitos que ocorrem antes, durante e após o brincar, julgam 
que há situações em que seus alunos não são capazes de resolver, resolução também eficiente quando desrespeitam as regras pré-estabelecidas.

Alguns consideram o momento do brincar como primordial e apenas tomam a atitude de observar. Outros já dizem interferir, quando convém, sem atrapalhar a brincadeira, para fazer perguntas pontuais e pertinentes ao contexto brincante. Há também um grupo de professores que apenas interferem quando pressentem uma iminente agressividade entre as crianças ou o risco de acidentes físicos.

A professora Marisa diz se preocupar quando as crianças fazem das peças de montar armas de brincar, alega intervir e orientar para que essas condutas sejam evitadas, pois, para ela "não é uma brincadeira legal", isto é, do bem, já que em sua visão "arma não é brinquedo". A professora Nazaré responde quando se dá sua intervenção: "Quando é necessário, nas resoluções de conflitos ou quando a atividade é direcionada, para alcançar os objetivos planejados, de forma sutil para não estragar a brincadeira [...]”. Assim como Nazaré, algumas das profissionais responderam o questionário mencionando a categoria de atividades dirigidas ou direcionadas.

Abaixo algumas das falas que mostram como são esses tipos de intervenções:

Às vezes. Quando surge conflito entre eles, na disputa pelo mesmo brinquedo ou quando é necessário fazer uma mediação para estipular regras. (Profa. Rosa - 30 anos).

Poucas vezes. Quando há briga por um determinado objeto e quando a atividade que estamos desenvolvendo pede. (Profa. Paula - 29 anos).

Às vezes. Entro na brincadeira por ex.: duas crianças brigavam porque o coleguinha queria o mesmo pedaço do bolo de chocolate, então entrei na brincadeira e falei: amiguinha porque não troca o bolo de chocolate por bolo de abacaxi? E resolveu a questão. (Profa. Maria -25 anos).

Há, ainda, professoras que preferem uma intervenção na brincadeiras e nos jogos, mas a propósito naquilo que podem escoar a uma outra alegoria, voltada à construção ou mesmo a uma viagem as suas reminiscências.

Às vezes. Eu proponho às crianças algumas brincadeiras que foram da minha infância... uma brincadeira mais simples e sutil, que não seja muito elaborada. (Profa. Luzia - 30 anos).

Às vezes. Quando noto que posso acrescentar algo na brincadeira faço intervenções, por exemplo, quando estão brincando de carrinhos e um quebra, eu falo: podemos construir uma oficina? etc. (Profa. Nair - 30 anos). 
Como se vê as intervenções são para resolver os problemas ligados à agressividade ou alguma forma de violência, mas há aquelas, em pequena minoria, que intervêm propondo um acréscimo na atividade, mudando a sua rota, sem se desgrudar da intenção maior da escola: estar à cata de novos conhecimentos.

\section{CONSIDERAÇÕES FINAIS}

As alegorias na forma de escrita, fala e ação das professoras nos conduziram a alguns desvelamentos sobre brinquedos e brincadeiras de crianças, sob o manto pedagógico do discurso e da prática.

Com o mantra sobre a importância do brinquedo, dos jogos e das brincadeiras no ambiente escolar, foi possível observar que os participantes os consideram essenciais, quando afirmam que estimulam à aprendizagem, auxiliam no processo de alfabetização, além de servirem para: entreter, descontrair a criança, trazer prazer e alegria, para desenvolver a flexibilidade motora, a oralidade, a criatividade, os aspectos emocional, afetivo e a fantasia.

O brinquedo figura como suporte, como motivação para a descoberta do outro e de si mesmo, favorece a interação social, a socialização, a manipulação de objetos novos, propicia a combinações de ideias quando estimula a criança a aprender a compartilhar, a dividir e a cooperar de livre e espontânea vontade, sem aquela obrigação moralista do dever ser.

Nenhuma das entrevistadas enxergam uma oposição entre o divertimento estéril e a instrução. Manson (2002, p. 242) descreve que os pedagogos iluministas alertavam para esse antagonismo entre brincar e estudar. Ratifica esse autor que "nas obras pedagógicas como nos livros para a juventude, exprime uma hierarquia de valores, onde o estudo leva a melhor sobre a brincadeira". Os autores contemporâneos de Rousseau recomendavam que ajudássemos as crianças a não ter repulsa pelo estudo, porque é feito de sacrifícios, mas que por outro lado não deveríamos "esconder os esforços necessários sob o manto falacioso e encantador do jogo". (MANSON, 2002, p. 242).

As intervenções das professoras nos ensinaram, de modo peculiar ela as fazem, mas quando lemos detidamente suas falas, a alegoria relevante dá-se na diligência policial, mais que na intervenção pedagógica. Estão mais preparados a intervir para dissolver conflitos, do que para a mediação de situações litigiosas ou, quem sabe apresentar uma sugestão para outros caminhos que trariam uma nova energia. 
São raros os professores que sugerem um desenho, uma fotografia, uma filmagem ou outra mídia tendo como mote os brinquedos e as brincadeiras, assim como são raros os professores que brincam com eles; que tentam extrair uma pauta para assuntos relevantes ou que proponham uma discussão de gênero, diversidade, precariedade do espaço escolar, a partir dos episódios litigantes que venha a irrigar uma conduta de risco.

Os professores intervêm para uma contenção, que nada tem a ver com a preservação e estimulação do ambiente lúdico. O que não significa que as crianças não devam ter um olhar de alguém que as cuide, nem tão pouco que se faça vistas grossas às possibilidades de incidentes que podem ocorrer nestes espaços brincantes. Porque as crianças, movidas por seu espírito lúdico, muitas vezes se põem em ciladas ou em situações de risco.

São raras, mas pelas vozes há espaço para intervenções criativas destes profissionais, quando são capazes de captar as situações de brincadeiras que se apresentam nos grupos infantis e aos poucos inserir objetos, brinquedos, ideias ou músicas, e imiscuindo-se, eles mesmos na situações brincantes, tornando assim mais um brincador.

Por fim, nota-se que os discursos sobre os brinquedos e brincadeiras na educação infantil denotam que os professores trazem em suas memórias narrativas lúdicas infantis e tentam, em algumas situações, reproduzir, com seus alunos, as brincadeiras que conhecem desde criança.

\section{REFERÊNCIAS}

ALMEIDA Paulo N. Educação Lúdica - técnicas e jogos pedagógicos. São Paulo: Loyola, 1990.

ARAÚJO, Maynard de. Folclore Nacional. São Paulo: Melhoramentos, v. 2, 1964.

BENJAMIN, Walter. Reflexões: a criança, o brinquedo, a educação. São Paulo: Summus, 1984.

BROUGÈRE, Gilles. Jeu et Éducation Paris: Harmattan, 1995.

CAILLOIS, Roger. Les jeux et les hommes: le masque et le vertige. Paris Éditions, Gallimard, 1967.

CAMARGO, Luiz O.L. Os interstícios da hospitalidade. Revista Hospitalidade, v. XII, n. especial, p. 42-69, 2015

CASCUDO, Luís da Câmara. Dicionário do folclore brasileiro. São Paulo: EDUSP, 1988.

CERVO, Amado. L.; BERVIAN, Pedro A. Metodologia científica. $5^{\mathrm{a}}$ ed. São Paulo: Prentice Hall, 2002. 
CHÂTEAU, Jean. O jogo e a criança. São Paulo: Summus, 1987.

GOMES, Cleomar Ferreira. Meninos e brincadeiras de Interlagos: um estudo etnográfico da ludicidade. 361 f. 2012. Tese (Doutorado em Educação) — Faculdade de Educação de São Paulo, São Paulo, 2001.

HOUAISS, Antônio e VILLAR, mauro de Salles. Dicionário Houaiss da Língua Portuguesa. Rio de Janeiro: Objetiva, 2007.

HUIZINGA, Johan. Homo Ludens: o jogo como elemento da cultura. São Paulo: Perspectiva, 1990.

LAKATOS, Eva M.; MARCONI, Marina de A. Fundamentos de Metodologia científica. $7^{\mathrm{a}}$ ed. São Paulo: Atlas, 2010.

MANSON, Michel. História do brinquedo e dos jogos: brincar através dos tempos. Lisboa: Teorema, 2002.

MANSON, Michel. In: GOMES, Cleomar Ferreira. Meninos e brincadeiras de Interlagos: um estudo etnográfico da ludicidade. 361 f. 2012. Tese (Doutorado em Educação) Faculdade de Educação de São Paulo, São Paulo, 2001.

PIAGET, Jean. A formação do símbolo na criança: imitação, jogo e sonho, imagem e representação. Rio de Janeiro: Guanabara, 1978.

SUTTON-SMITH, Brian. The ambiguity of play. Cambridge, MA, USA: Harvard University Press, 1997.

TOBIN, Joseph Jay. Making a place for pleasure in Early Childhood Education. U.S.A: Yale University Press, British Library, 1997.

Artigo recebido em: 20/08/2018

Avaliado em: 29/08/2018

Aprovado em: 30/08/2018 